\title{
A Rare Injury in Children: Sternum Fractures
}

\author{
Department of Thoracic Surgery, Kayseri City Training and Research Hospital, Kayseri, Turkey
}

\begin{abstract}
Although there are a lot of data on intrathoracic and extrathoracic injuries associated with adult sternal fractures and how to manage them; but there is not much data on diagnosis and treatment protocols, since they are rare in children. If the child patient has a sternal fracture, he/she probably had a high-energy trauma, so it should be carefully examined whether if there is an accompanying intrathoracic or extrathoracic injury. In this study, we aimed to determine the demographic data, accompanying injuries, treatment modalities and results in children who were admitted to the emergency trauma unit of our hospital and diagnosed with sternal fracture.
\end{abstract}

Key Words: Sternum fracture, Injury, Trauma.

How to cite this article: Ozsoy IE, Tezcan MA. A rare injury in children: sternum fractures. J Coll Physicians Surg Pak 2019; 29(10):993-5.

\section{INTRODUCTION}

Sternal fractures are rarely encountered after blunt thoracic trauma in children; and are rarely reported in the literatüre. 1-3 If the child patient has a sternal fracture, he/she probably had a high-energy trauma, so it should be carefully examined whether there is an accompanying intrathoracic or extrathoracic injury. 4

This study aimed to determine the demographic data, accompanying injuries, treatment modalities, and results in children who were admitted to the emergency trauma unit of our hospital and diagnosed with sternal fracture.

\section{METHODOLOGY}

After obtaining permission from the Department of Thoracic Surgery, Kayseri City Training and Research Hospital, Kayseri, Turkey, and Hospital Education Board, data from the Hospital Information Management System were reviewed retrospectively. Children with a diagnosis of sternum fracture were included. Chest X-ray and thoracic computerised tomography (CT) images were evaluated by a radiologist and the diagnosis was confirmed. The patients were evaluated in terms of demographic findings, type and etiology of the trauma, fracture localisation and diagnosis method, clinical findings, concomitant intrathoracic and extrathoracic injuries, treatment method, intensive care unit requirement, total hospitalisation period and results. The coding and statistical analysis of the data were performed in the SPSS version 22 package programme. The numerical

Correspondence to: Dr. Ibrahim Ethem Ozsoy, Department of Thoracic Surgery, Kayseri City Training and Research Hospital, Kayseri, Turkey

E-mail: ibrahimethem.ozsoy@sbu.edu.tr

Received: December 05, 2018; Revised: March 26, 2019;

Accepted: March 26, 2019 values obtained were expressed as mean \pm standard deviation and categorical values were expressed as median \pm minimum-maximum (median \pm min-max).

\section{RESULTS}

In the 6 years between January 2012 and January 2018, a total of 225 thousand (mean 37.5 thousand / year) minor / major trauma children aged 0-18 years were brought to our emergency pediatric trauma unit. Ten patients were diagnosed with sternal fracture. Only one $(10 \%)$ of the patients were female and the mean age was 11.8 (range 3 to 18) years. All patients had blunt trauma. Six patients $(60 \%)$ were brought to the hospital as a result of falling from a height of 1-2 meters (for example from a swing or a wall). All patients had pain and tenderness on the sternum. The 3-year toddler who was brought to the hospital due to a traffic accident, had fractures in both manubrium and body, one sternebra and had right pneumothorax, lung contusion and substernal hematoma; tube thoracostomy was performed

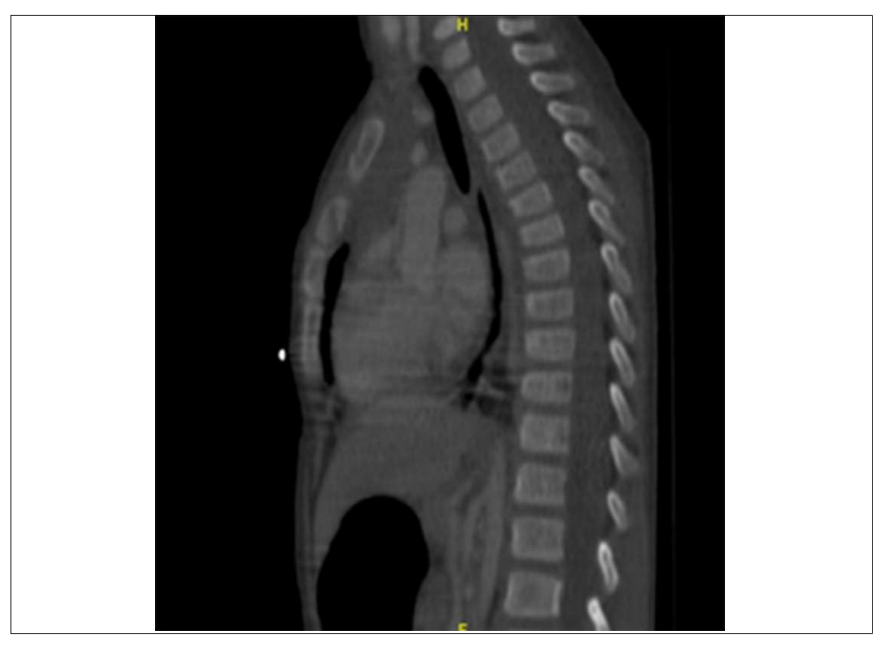

Figure 1: X-ray findings in manubrium and body fractures (CT- scan). 
Table I: Demographics of patients with sternal fractures.

\begin{tabular}{lc}
\hline & $\mathrm{N}$ \\
\hline Age (y), mean (range) & $11.8(3-18)$ \\
\hline Gender (male/female) & $9 / 1$ \\
\hline Location of sternal fractures & 1 \\
Manubrium & 1 \\
Manubrium + body & 8 \\
Body & $6(60 \%)$ \\
\hline Cause of injury & $2(20 \%)$ \\
Fall from a height & $2(20 \%)$ \\
Fall from bicycle & 1 \\
Motor vehicle accident & 1 \\
\hline Associated injuries & 2 \\
Rib fracture & 1 \\
Lung contusion & $3(30 \%)$ \\
Pneumothorax & 0 \\
Retrosternal hematoma & 1 \\
Chest X-ray (diagnostic) & 0 \\
\hline Electrocardiography (pathological) & $2.6(1-6)$ \\
\hline Echocardiography (pathological) & (retrosternal hematoma) \\
\hline Surgical procedure for sternal fracture & \\
\hline Hospital stay (days) & \\
Mean (range) & \\
\hline
\end{tabular}

(Figure 1). In the patient who was brought to the hospital because of falling from a swing, a costae fracture and right pneumothorax was accompanying to sternum fracture and tube thoraco-stomy was performed. All patients were hospitalised and monitored for cardiac rhythm follow-up. An appropriate dose of analgesic and oxygen was administered. Only one patient was given prophylactic antibiotics, since he was followed up in the intensive care unit. Rest of the patients were discharged. All data concerning the patients with sternum fractures are given in Table I.

\section{DISCUSSION}

There are very few reports of pediatric sternal fractures, and almost all of these are case reports. ${ }^{1-3}$ In a limited number of publications, the incidence of sternal fracture in children is reported between 0.5 and 3\%.5,6 While 24 thousand child patient were brought to the emergency trauma unit of our hospital in 2012, 28 thousand in 2013, 33 thousand in 2014, 39 thousand in 2015, 47 thousand in 2016, and 54 thousand in 2017. In those 6 years, sternum fracture was detected in 10 children. Instead of reporting an incidence rate, it is believed that an expression in this way is more accurate. Among approximately 225 thousand pediatric trauma patients who were brought to the emergency trauma unit in 6 years, although only 10 sternum fractures, appear to be very few, is an accurate number, because CT was performed in patients with suspected fractures and the diagnosis was not missed.

Particularly young children may not be able to fully show the painful areas of the body. Hematoma, edema, ecchymosis and contusion can be seen on the sternum during the inspection. When the sternum is palpated, if there is sensitivity and mild/severe pain, further examination should be performed. Irregularity on the sternum by palpation is not seen in all patients. ${ }^{7}$

Posteroanterior thorax radiographs provide a rough evaluation of the mediastinum and shows if there is accompanying rib fracture, hemothorax or pneumothorax. Lateral chest radiographs are very difficult to interpret in a child, if the fracture is not dissociated. If there is a very small fracture in the cortex, it will be overlooked. Therefore, if there is a suspicion of fracture, thorax CT should be applied not to overlook fracture or accompanying intrathoracic pathologies. 8 Only three patients had fracture on the lateral thorax graphy, the other seven patients were diagnosed by CT. The low diagnostic rate with lateral radiography may be due to the fact that those patients do not stay very stable during the X-ray imaging because they were very young, and the surrounding soft tissues were superposed, and consequently the quality of the image is poor. Only five patients had cortex fracture. This suggested that the diagnosis would be difficult with lateral radiography.

There are clinics that often use ultrasonography, if there is a suspicion of fracture. ${ }^{9}$ Since, there were not enough radiologists, ultrasonography could not be routinely used. Pericardial tamponade and mediastinal hematoma were observed in patients with sternum fractures. Thus patients should be carefully evaluated for myocardial contusion. The patients' electrocardiography, creatine kinase and creatine kinase-myocardial band levels should be examined at the time of presentation.10,11 In cases of doubt, echocardiography, which is the most appropriate and fastest diagnostic method, should be applied. In only one patient, a substernal hematoma with a millimetric size was seen on echocardiography. Myocardial contusion was not observed in any patient. The enzyme levels of the patients were normal. All patients were hospitalised and monitored for cardiac rhythm follow-up. There are publications reporting that patients without accompanying injuries are discharged from the emergency department. 12 Instead of discharging from the emergency department after the patients were diagnosed, it was preferred to hospitalise them for a short time. Only two of 10 patients had accompanying injury and so tube thoracostomy was performed. The other 8 patients had isolated injuries and could be sent home from the emergency department, but due to possible complications within the next 24-48 hours, they were hospitalised and given analgesic anti-inflammatory treatment. No additional pathology developed in any of the patients admitted to the hospital. Surgical stabilisation is not needed in children.

Treatment of additional injury prolongs hospitalisation. Eight patients were hospitalised for 24-48 hours, but 2 patients with pneumothorax and costal fractures were hospitalised for 5-6 days. 
Isolated sternum fracture in children is not terrible. It is necessary to carefully investigate the pathologies that may accompany. In terms of possible complications, the most appropriate approach is to follow up the patients for 24-48 hours at the hospital.

\section{CONFLICT OF INTEREST:}

Authors declared no conflict of interest.

\section{AUTHORS' CONTRIBUTION:}

IEO: Concept, design, data collection, analysis, literature search and writing.

MAT: Concept, design, data collection, analysis and literature search.

\section{REFERENCES}

1. Ferguson LP, Wilkinson AG, Beattie TF. Fracture of the sternum in children. Emerg Med J 2003; 20:518-20.

2. DeFriend DE, Franklin K. Isolated sternal fracture - a swingrelated injury in two children. Pediatr Radiol 2001; 31:200-2.

3. Pérez-Martínez A, Marco-Macián A, Gonzálvez-Piñera J, Agustí-Buztke B, Solera Santos G. Cortical fracture of the sternum in a child: An infrequent case. Cirugia Pediatrica 1996; 9:130-1.

4. Templeton JM. Thoracic trauma. In: Fleisher GR, Ludwig S, eds. Textbook of pediatric emergency medicine. Baltimore: Williams and Wilkins, 1993:1143-66.
5. Mayberry JC, Ham LB, Schipper PH, Ellis TJ, Mullins RJ. Surveyed opinion of American trauma, orthopedic, and thoracic surgeons on rib and sternal fracture repair. $J$ Trauma 2009; 66:875-9.

6. Loder RT, Schultz W, Sabatino M. Fractures from trampolines: Results from a national database, 2002 to 2011. J Pediatr Orthop 2014; 34:683-90.

7. Soysal Ö, Akdemir OC, Ziyade S, Ugurlucan M. Management of sternal segment dislocation in a child with closed reduction. Case Rep Med 2012; 2012.

8. Hsiao V, Santillanes G, Malek D, Claudius I. Review of interventions and radiation exposure from chest computed tomography in children with blunt trauma. J Pediatr 2018; 198: 220-5.

9. Sesia SB, Prüfer F, Mayr J. Sternal fracture in children: Diagnosis by ultrasonography. European J Pediatr Surg Rep 2017; 5:e39-e42.

10. Celik B, Sahin E, Nadir A, Kaptanoglu M. Sternum fractures and effects of associated injuries. Thorac Cardiovasc Surg 2009; 57:468-71.

11. Gouldman JW, Miller RS. Sternal fracture: A benign entity? Am Surg 1997; 63:17-9.

12. Kouritas VK, Zisis C, Vahlas K, Roussakis AG, Bellenis I. Isolated sternal fractures treated on an outpatient basis. Am J Emerg Med 2013; 31:227-30. 